\title{
Numerical simulation of a crack emanating from a micro-cavity in the orthopedic cement by technical sub modeling of total hip prosthesis
}

\author{
Zahi Rachid \\ University Center Abmed ZABANA -Relizane, Algeria \\ zahirachid72@yahoo.fr
}

Ait Kaci Djafar, Sahli Abderahmane,

Laboratory of Mechanics, Physics of Materials. University of Sidi Bel Abbes 22000, Algeria.

sablaabderahmen@yahoo.fr, bttps://orcid.org/0000-0002-5183-1168

\author{
Moulgada Abdelmadjid \\ Department of Mechanical Engineering, Ibn khaldoun University Tiaret, 14000, Algeria \\ amoulgada@hotmail.fr
}

\section{Benbarek Smail}

Laboratory of Mechanics, Physics of Materials. University of Sidi Bel Abbes 22000, Algeria sma_benbarek@yahoo.fr, https:/ /orcid.org/0000-0002-7420-9144

\begin{abstract}
In orthopedic surgery and particularly in the total hip arthroplasty (THP), the stem fixation is performed in general using surgical cement which consists essentially of poly (methyl methacrylate) (PMMA). Fracture of cement and prosthesis loosening appears after high concentrations of stress. This phenomenon origin is due to the presence of micro-cavities in the cement volume due to patient movements. The focus of this study is the modeling using the finite element method of a crack emanating from a cavity. It was assumed several positions and orientations of the crack in the cement to calculate the stress intensity factor (SIF). Results show that the presence of a crack emanating from a cavity in the cement increases the risk of fracture of cement.
\end{abstract}

KEYwORDs. Bone Cement; Crack; Total Hip Prosthesis; Stress Intensity Factor.
OPEN O ACCESS

Citation: Rachid, Z. Djafar, A. K. Abderahmane, S., Abdelmadjid, M., Smail, B., Numerical simulation of a crack emanating from a micro-cavity in the orthopedic cement by technical sub modeling of total hip prosthesis, Frattura ed Integrità Strutturale, 49 (2019) 586-598.

Received: 15.12.2018

Accepted: 08.05.2019

Published: 01.07.2019

Copyright: (C) 2019 This is an open access article under the terms of the CC-BY 4.0, which permits unrestricted use, distribution, and reproduction in any medium, provided the original author and source are credited. 


\section{INTRODUCTION}

$\mathrm{D}$ uring total hip arthroplasty, the surgeon replaces the two surfaces of the natural joint (the femoral head and the acetabulum of the iliac bone) with two prosthetic components: the cupule and the femoral implant. Total Hip Arthroplasty (THP) has become the second most common surgical procedure performed annually [1]. In THP, two types can be distinguished depending on the method of fixation of the implant in the patient's bones, cemented or uncemented. In both methods, the stability of the prosthesis in the bone plays an important role in the long-term durability of THP [2]. In the cemented femoral prosthesis, the structural resistance of the THP is provided by the cement, which must withstand the mechanical stresses that can potentially lead to the generation and propagation of cracks and the possible failure of the entire THP structure [3, 4].

PMMA has important micro structural heterogeneities such as cavities, and its elastic behavior is greatly affected by the presence of defects that may imply its weakening and cause failure $[4,5]$. In areas of high concentrations of stress and due to the presence of micro cracks appear after crushing cavities due to patient movement; these micro cracks grow and weld to each other until they form a macro fissure that propagates until the total removal of the prosthesis $[6,7]$. The notions of elastic linear mechanics of fracture, such as the stress intensity factors, the rate of energy restitution, precisely describes the behavior of cracks in fragile materials whatever the state of the fracture geometry and loading [8]. The use of these concepts can be an effective tool for analyzing the fracture behavior of orthopedic cement, which constitutes a predictive tool of pre/post-evaluation device of cemented acetabular reconstructions.

The study of the risk of fracture that comes from a crack emanating from a cavity is made according to the most dangerous orientation and position of the micro-cavities in the cement [9]. The investigation crack failure from a mixedmode cavity at different zones in the cement, the majority of previous studies have been performed using twodimensional (2D) models for the analysis of fissure in orthopedic cement using the finite element method [8]. Three types of cracks can be identified in orthopedic cements, fissures emanate from a cavity; crack initiated during polymerization and cracks initiated in cement by internal stresses $[9,10]$.

To better understand the problems of loosening of femoral prostheses, it was developed a digital mechanical model of the "femur, cement, implant" system [11,12], it represents the prosthesis in its anatomical environment. While a significant challenge, the incentive to carry out 3D modeling of crack behavior and the compute stress intensity factors of three dimension crack in the cement is the ability to predict the cement mantle reliability from nondestructive inspection of implants such as high resolution micro tomography that can reveal the presence of cracks in the cement $[13,14,15]$.

In this study, the existence of a crack emanating from a cavity was assumed; its assessment takes into account two parameters, the position of the crack in the cement and the stress intensity factor (SIF) that was calculated in the proximal part of orthopedic cement.
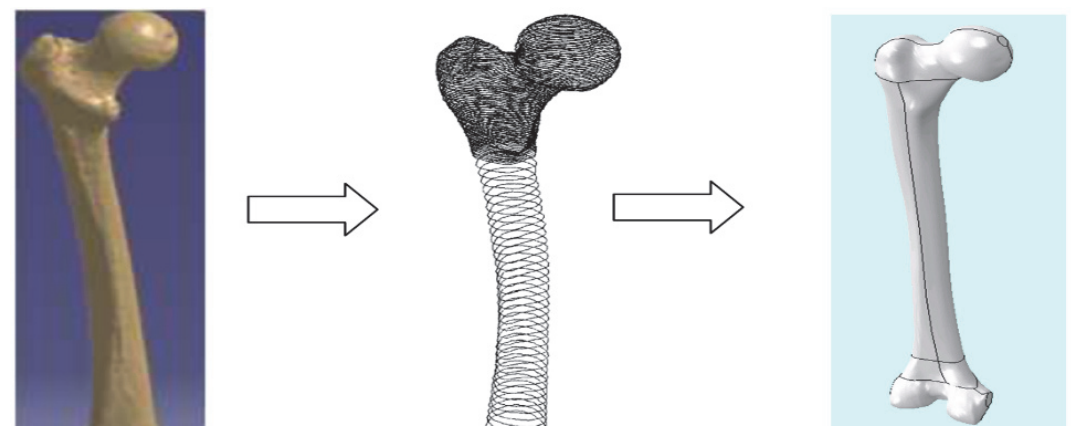

Figure 1: Digitization of the femoral bone.

\section{THREE-DIMENSIONAL MODELING}

\section{Geometric model}

btaining the solid 3D model of a patient's femur involves taking images of the region of interest using a medical imaging technique (CT-scan).The thickness of each slice is from $1 \mathrm{~mm}$ for the proximal part to the small trochanter and $8 \mathrm{~mm}$ from the small trochanter to the most distal part of the diaphysis. Using the brightness of 
tomographic images; two regions can be distinguished (cortical bone and cancellous bone). The 3D reconstruction of the two regions is done separately. Fig.1 shows the steps of 3D reconstruction of the femur [16, 17].

Cement, implant and femur assembly was performed using SolidWorks software, the positioning of the prosthesis with respect to the femur was performed in order to give a junction close to that actually reconstructed by the surgeon. Fig. 2 shows a section of the reconstructed junction, the position of the prosthesis is made so that the orthopedic cement has a uniform thickness of $2 \mathrm{~mm}$ around the implant to homogenize the transfer of loads to the bone.

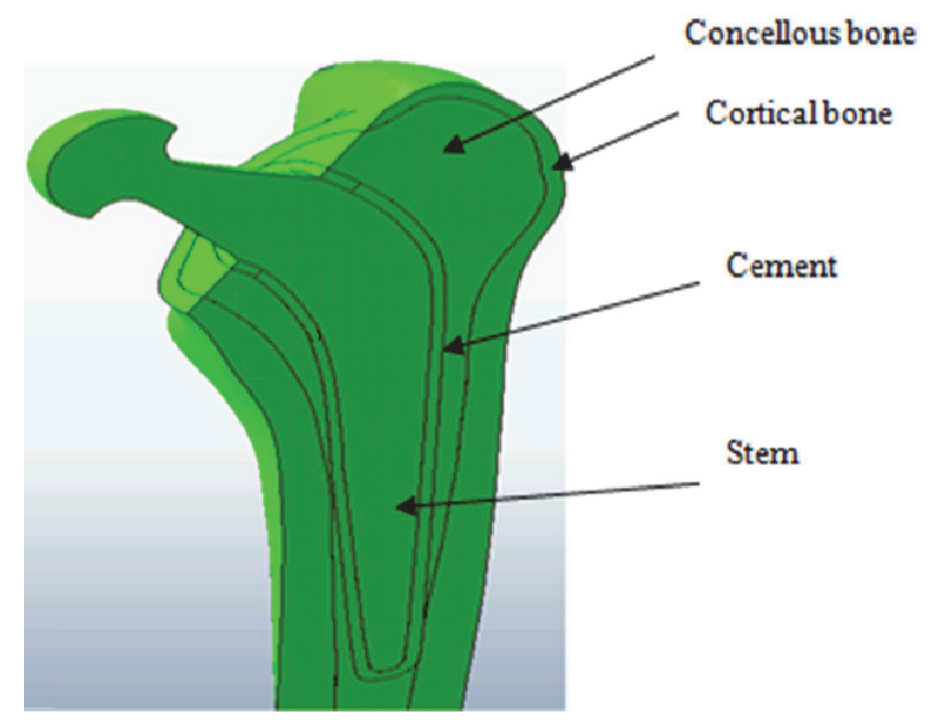

Figure 2: 3D model of the total hip prosthesis.

Fig. 3 shows the components of the femoral prosthesis, it is noted that the orthopedic cement is in direct contact with the cortical bone. The used prosthesis is a standard CMK3 type prosthesis [18, 19, 20]. The 3D computer aided design (CAD) model of the human's femur is given by Pacific Research Labs [21]. The CAD model is composed of two regions: cortical bone and spongious bone. The three dimension reconstitution of both parts is realized separately and assembled. The Charnley-Muller-Kerboul third generation (CMK3) prosthesis is designed using the Solidworks Software [22] and includes the assembly of all parts of the prosthesis into one CAD model.

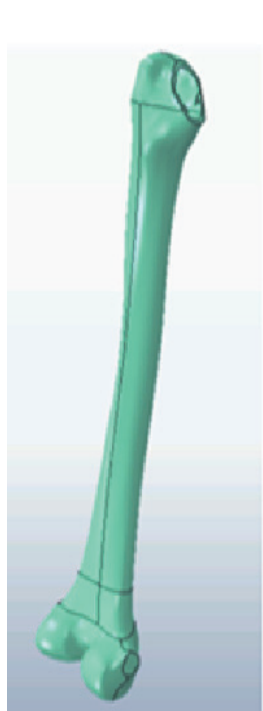

(a)

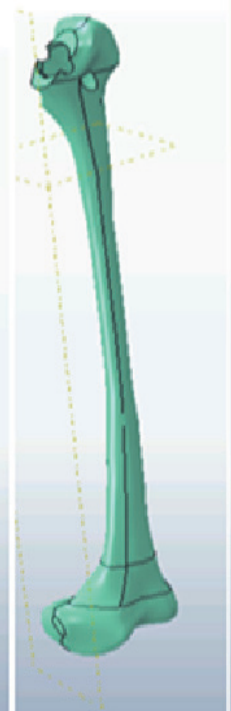

(b)

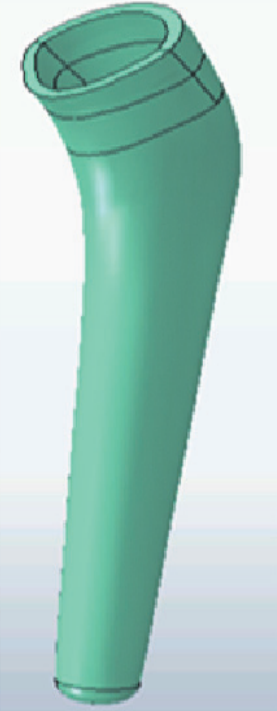

(c)

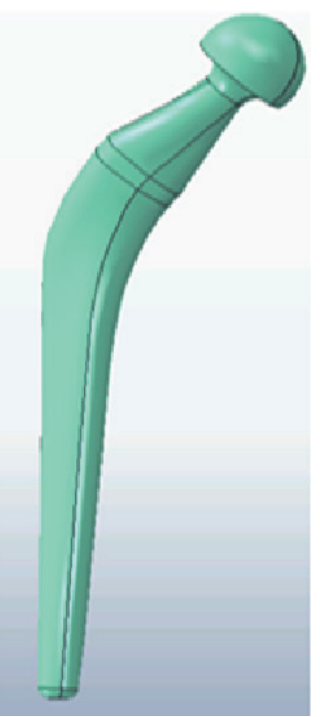

(d)

Figure 3: Three-dimensional model of the total hip prosthesis (a), Cortical bone, (b) Cancellous bone, (c) Cement, (d) Implant. 
Mechanical properties

In this study the mechanical properties of the components of the femoral prosthesis were taken from previous work $[5,7$, 9, 13, 23]. Benbarek et al. [9] considered the cortical and cancellous bone, implant, and orthopedic cement as elastic and isotropic materials (Tab. 1).

\begin{tabular}{ccc}
\hline Material & Young's modulus E $(\mathrm{MPa})$ & Poisson ratio $v$ \\
Cortical Bone & 17000 & 0.30 \\
Cancellous Bone & 2000 & 0.30 \\
Cement PMMA & 2300 & 0.30 \\
Stem & 210000 & 0.30 \\
\hline
\end{tabular}

Table 1: The artificial hip components material properties

This study is based on works done by [17] and [18] related to loads executed on the basin. The intensity of the compressive force executed during the monopodal support period is about 4 times the weight of the body, or $250 \mathrm{~kg}$ for a person weighing $70 \mathrm{~kg}$ in monopodal position, the value of $2.5 \mathrm{KN}$ is chosen to perform of finite element calculations on the femoral prosthesis. The distal part of the femur is embedded (Fig. 4); the contact between the different components of the THP is considered as continuous rigid.

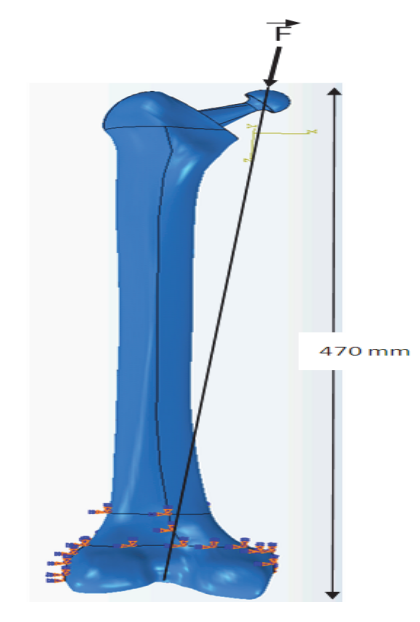

Figure 4: Boundary conditions.

\section{Finite ELEMENT MODEL}

\section{Technical sub modeling}

T $\mathrm{n}$ a sub-model analysis integrated into the Abaqus software, the complete model is separated into two distinct models: a global model and a sub-model (Fig.5), the global model contains the total geometry, the loading and the boundary conditions, the sub-model that is the object of the study (a crack emanating from a cavity) is specified as an arbitrary part taken from the global model, the sub-model keeps the same characteristics of the global model including the original coordinate system [13].

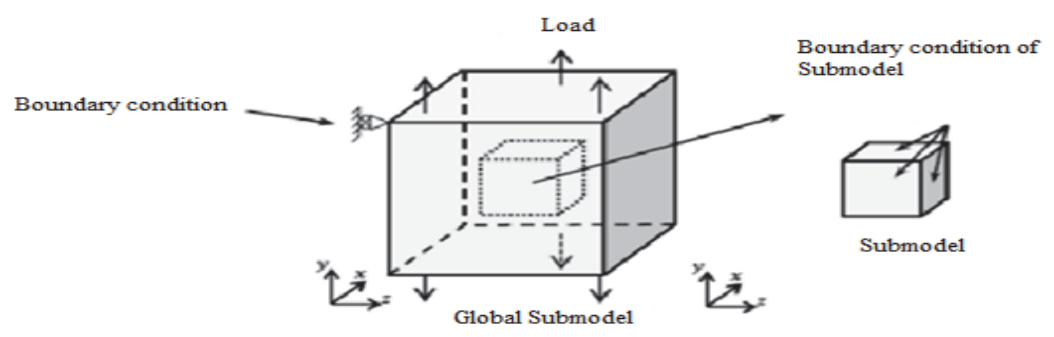

Figure 5: Representation of the global model and sub-model. 
The global model is solved first to obtain the overall response because of applied loads and boundary conditions. In the sub-model, the solution from the global model is then interpolated to the surface with appropriate interpolation functions. The sub-model can be solved separately, with a response applied from the global model. The link between the two models is defined at the intersection surfaces by boundary conditions. There are two approaches in Abaqus for these connections, node-based connection and surface connection. In this study, the node based connection is used. This technique is used to study the behavior of a crack inside the orthopedic cement. Fig. 6 shows the sub-model designed for failure analysis of cement. The crack is clearly defined on the inside. The reasons to opt for this technique are:

-The global model only needs one calculation.

-Simplified the change of the orientation and the positions of the crack.

-From the numerical point of view, the application of this method makes it possible to obtain a saving of computation time compared to the computation on the global model. Three zones, proximal, medial and distal (Fig. 6.(a)) were chosen on each zone, the fissure was placed in 8 positions along the orthopedic cement (Fig. 6.(c)). For each position the angle of the inclination of the crack is varied around the axis of rotation with a step of 15 degrees with respect to the sagittal plane (Fig. 6.(d)).

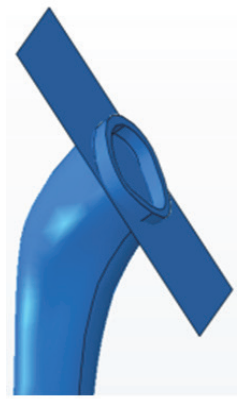

(a)

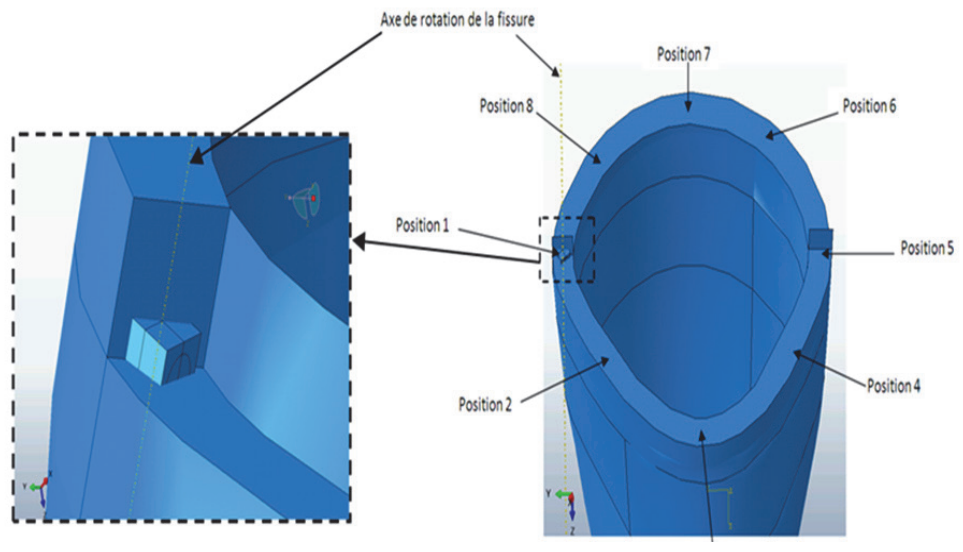

(b)

(c)

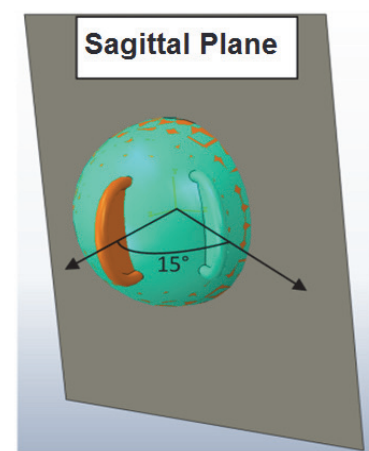

(d)

Figure 6: Zone and positions of the crack: (a) zone of the cracks, (b) close-up the crack submodel in the cement mantle, (c) the crack positions and (d) the crack orientation.

\section{Micro cavity}

Fracture of the cement mantle in cemented total hip replacements is often indicated as a precursor to eventual clinical loosening of the implant [23]. One factor that could affect the fracture toughness is porosity, although some investigators have suggested otherwise [24]. Since, pores have been identified in vitro as stress risers and crack initiators [20, 21]; higher degrees of porosity may contribute to microcracking [11, 19]. Generally, the cement rupture is caused by the accumulation of the cracks initiated from microcavities and in different orientations (Fig. 7) [24, 25].
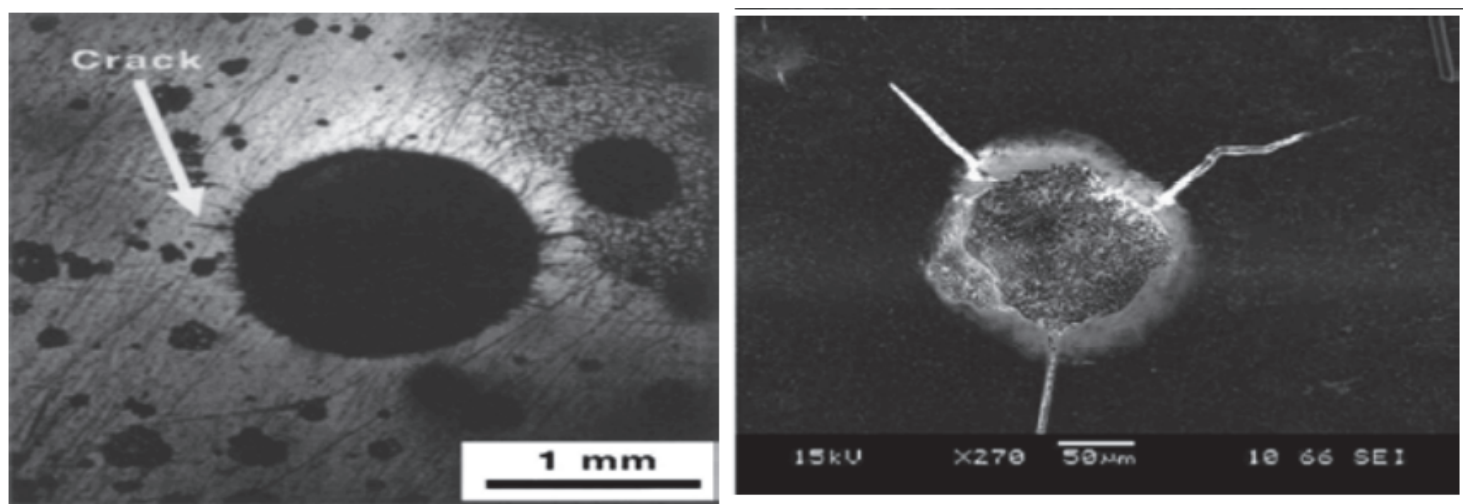

Figure 7: Crack emanating from microcavity in the cement [24]. 
It is assumed that there is a circular crack of $100 \mu \mathrm{m}$ diameter emanating from a spherical cavity $200 \mu \mathrm{m}$ in diameter in the orthopedic cement (Fig. 8).
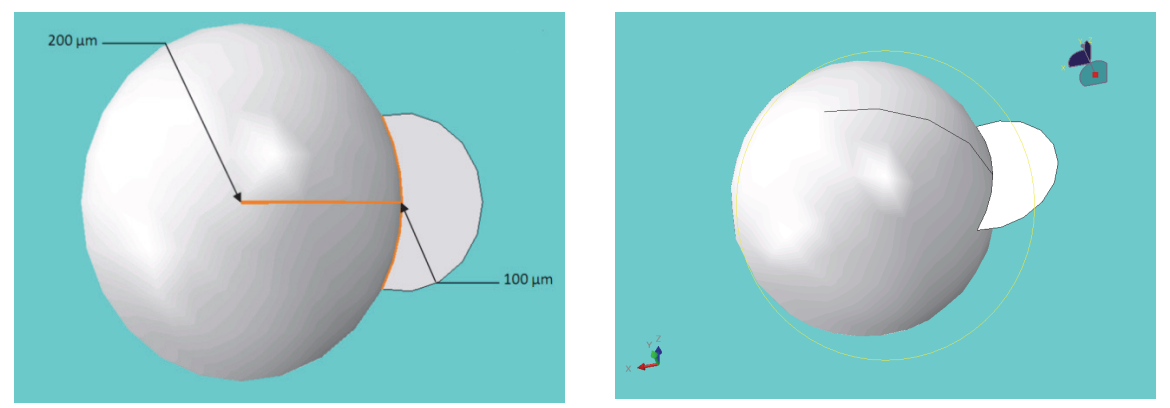

Figure 8: The shape of the defect.

\section{Meshing}

Recall that in this case, the same mesh of cortical bone and cancellous bone and implant as the previous analysis are used. Fig. 9 represents the three types of orthopedic cement mesh (global model) used and its refinement for the three zones studied proximal, medial and distal respectively. The mesh is done using hexahedral quadratic element (C3D20) for the area of interest and tetrahedral quadratic element (C3D10) for the remaining parts of the THR.

The mesh parameters are also introduced in order to control elements size and number in various areas of THA. For the Charnley model CMK3 has in total 27632 elements, cement 135461 elements and for the cortical and cancellous bone has 87944 and 51571 elements respectively.
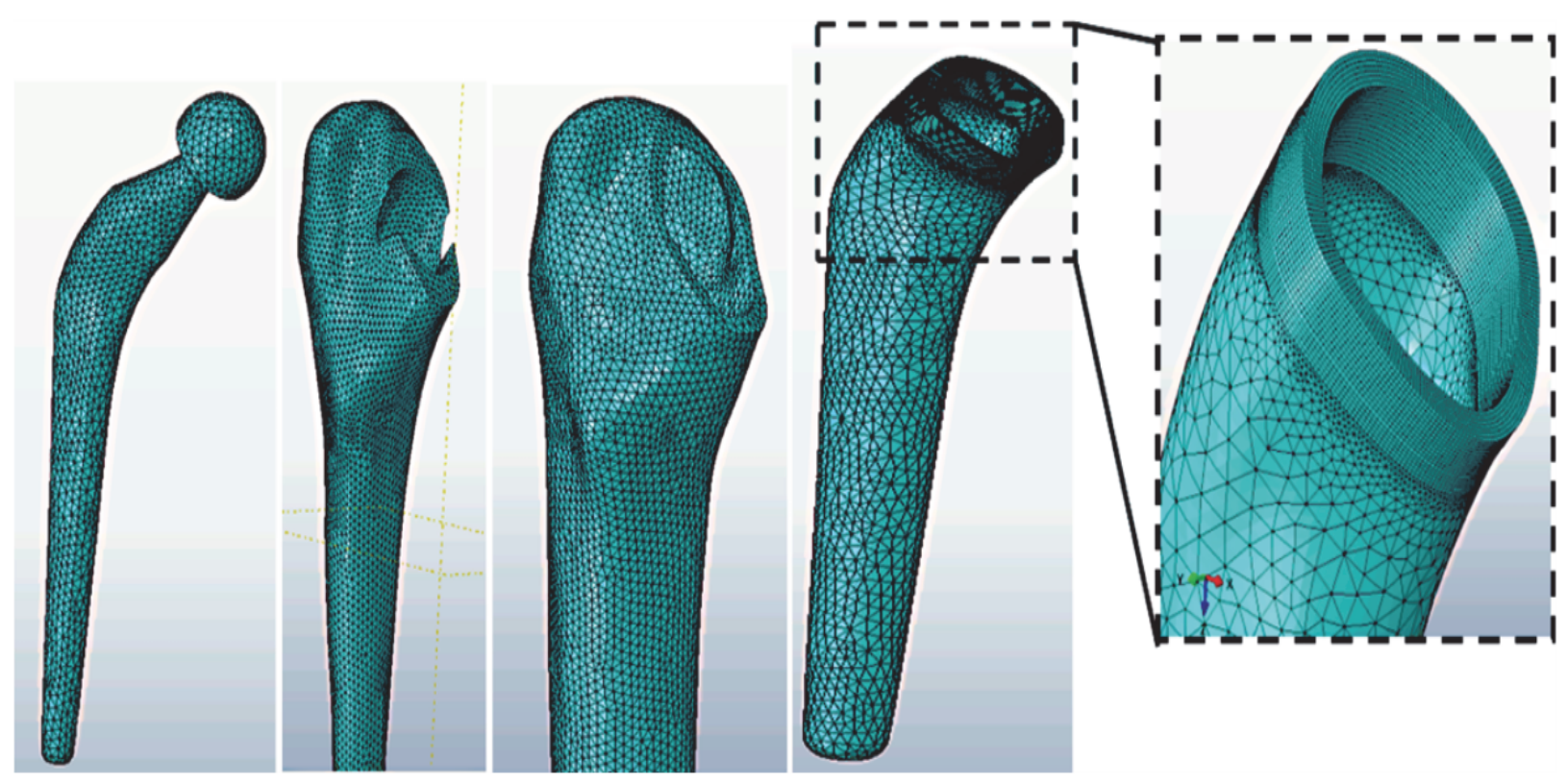

Figure 9: Mesh of the different parts of the THR with refined meshing of the proximal region of the cement.

The determination of stress intensity factor at the crack tip requires a highly refined mesh with proper element selection (C3D20) to gives results close to the reality for the sub-model has in total 10352 elements. In fact, the cement is a determinant element of the prosthesis and the refinement of its mesh is of great importance for the structure analysis. Fig. 10 shows the mesh of the total hip prosthesis different components. This figure shows a highly refined mesh around our studied area, the proximal region, to provide a good approximation of the displacement in the vicinity of the sub-model's region and to calculate the stress intensity factors. The surrounding mesh of the crack front must be specially meshed as shown in Fig. 9. 

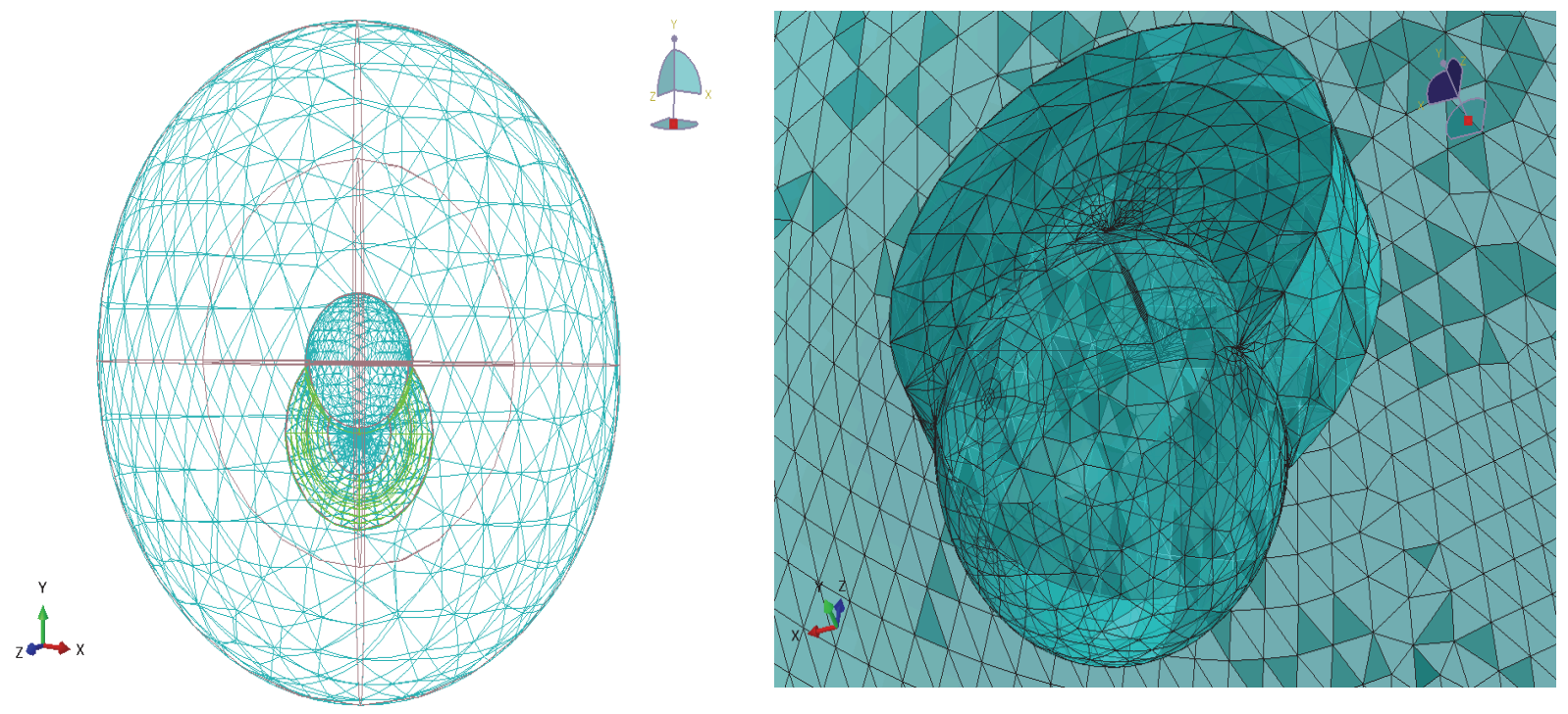

Figure 10: Meshing to the sub-model.

\section{RESULTS AND DISCUSSION}

he stress intensity factor characterizes the stress field and the displacement at the tip of the crack; it has a direct influence on crack propagation in the monotonic or cyclic loading [3, 18]. In order to compare the behavior of cracks emanating from a cavity, variation of the stress intensity factor as a function of the crack orientation for different positions in the three zones is represented: proximal, medial and distal, along orthopedic cement, the mesh on the bottom crack is well refined, a crack length $0.1 \mathrm{~mm}$ supposed initiated from the end of a spherical cavity diameter 0.2 $\mathrm{mm}$.

\section{Comparison of KI for different crack positions in the proximal part of the cement}

Fig. 11 shows the distribution of the Mode I stress intensity factor on the crack front as a function of the crack orientation emanating from a cavity, for different positions of the proximal zone, in this figure it note that in the 8 positions only 4 positions $(1,2,4$, and 5 ) show a risk of crack propagation since they give positive values of SIF (KI). In these 4 positions, the 1 st and the 5 th position are the most dangerous because KI values are the most important. For position 1 the $\mathrm{KI}$ is positive for a crack orientation between $\left[90^{\circ}\right.$ to $180^{\circ}$ ] and $\left[270^{\circ}\right.$ to $380^{\circ}$, whereas for position 5 , the stress intensity factor in opening mode is positive for the crack orientation intervals between $\left[15^{\circ}\right.$ to $\left.105^{\circ}\right]$ and $\left[180^{\circ}\right.$ to $270^{\circ}$ ], they can reach values of $4.5 \mathrm{MPa} \sqrt{\mathrm{mm}}$.

The values of stress intensity factors resulting from a crack emanating from a spherical cavity in position 1 and 5 are approximately symmetrical. The behavior of the SIF (KI) along the crack front shows a similar sinusoidal graph for the different positions of the crack with a period of $180^{\circ}$; this means that the KI values are symmetrical with respect to the sagittal plane.

In Fig. 12, is presented the interval in which the crack is open and this is the most critical orientations at this level for the four positions (1, 2, 4 and 5). It notes that positions 1 and 5 give higher values of KI. When the crack is at position 5 , the $\mathrm{KI}$ values are positive when the crack orientation is between $0^{\circ}$ and $180^{\circ}$, in this position is the opposite of the position 1 , so that it gives similar values, but in the opposite directions, positions 1 and 5 are the most dangerous positions of the crack that can lead to crack creation and propagation in the orthopedic cement mantle. For the other positions (position: $2,3,4,6,7$ and 8 ), there is no risk of propagation of the crack or it is very weak, because of the low or negative values of the intensity of stress. 

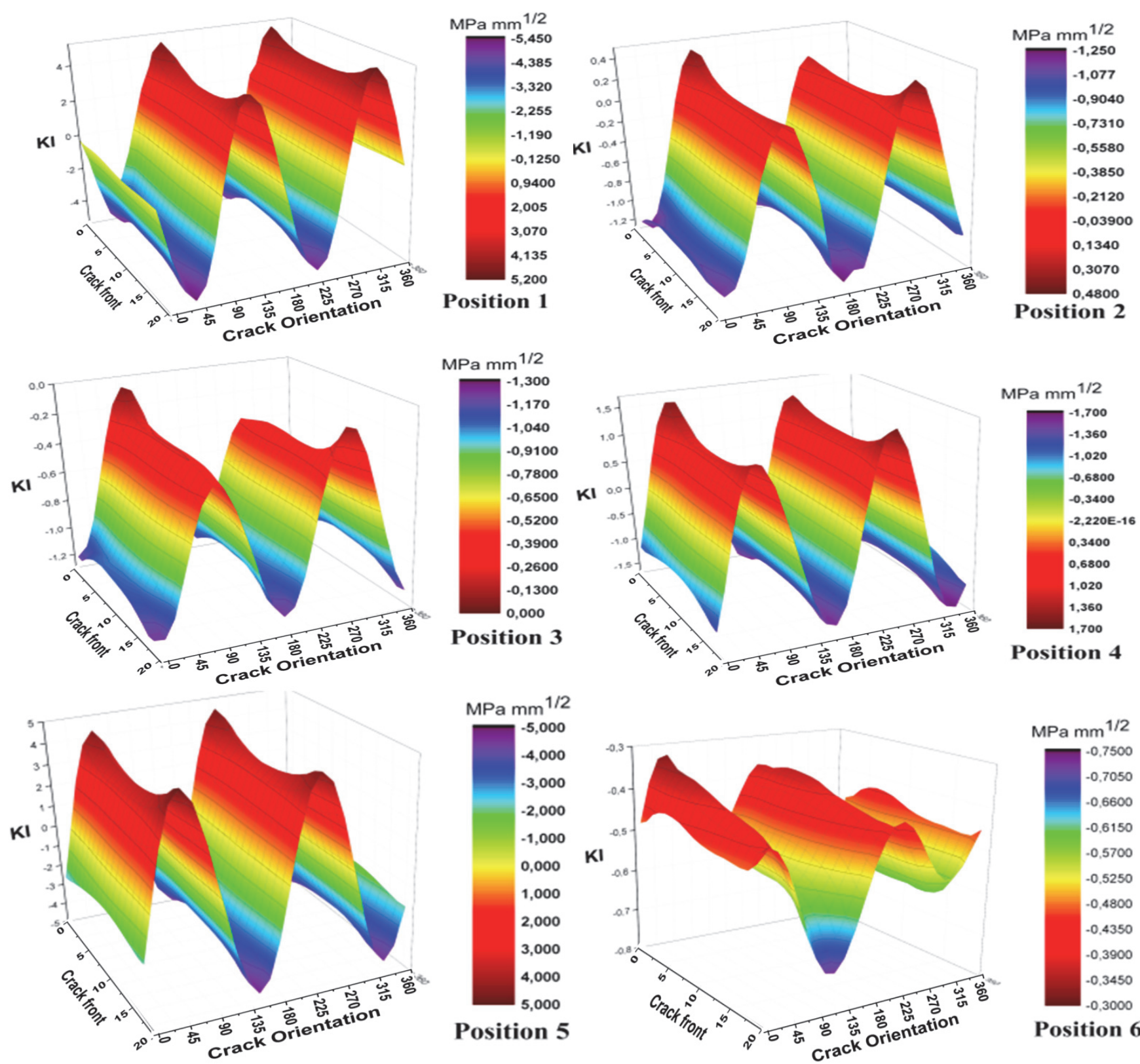

MPa $\mathrm{mm}^{1 / 2}$

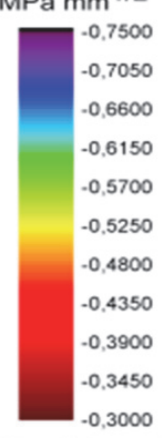

Position 5

Position 6

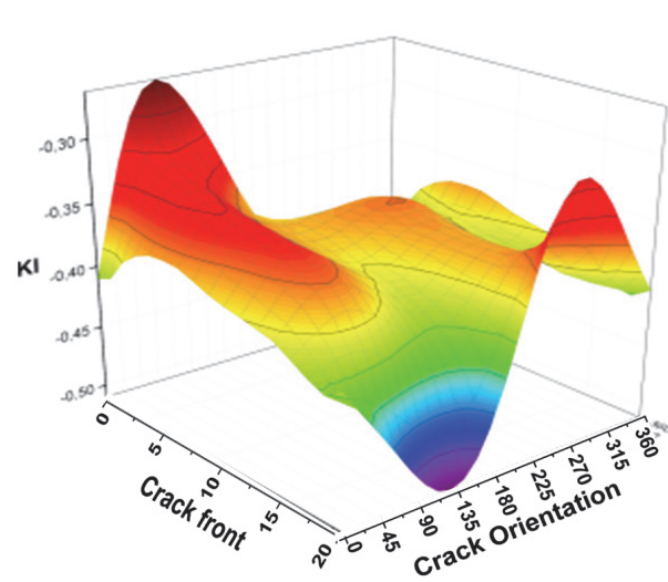

MPa $\mathrm{mm}^{1 / 2}$
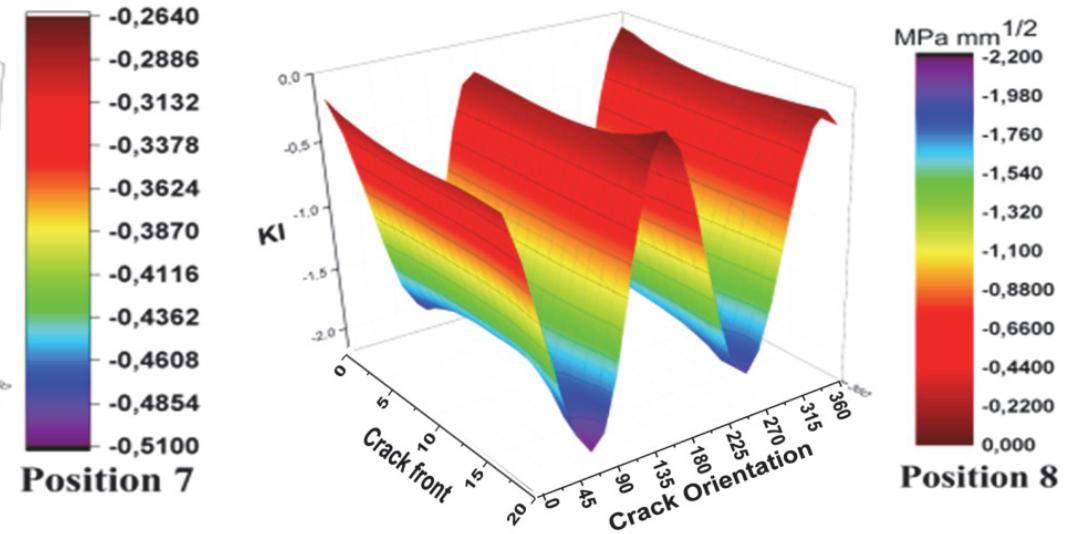

Figure 11: Distribution of the (KI) on the crack front according to the orientation of the crack. 


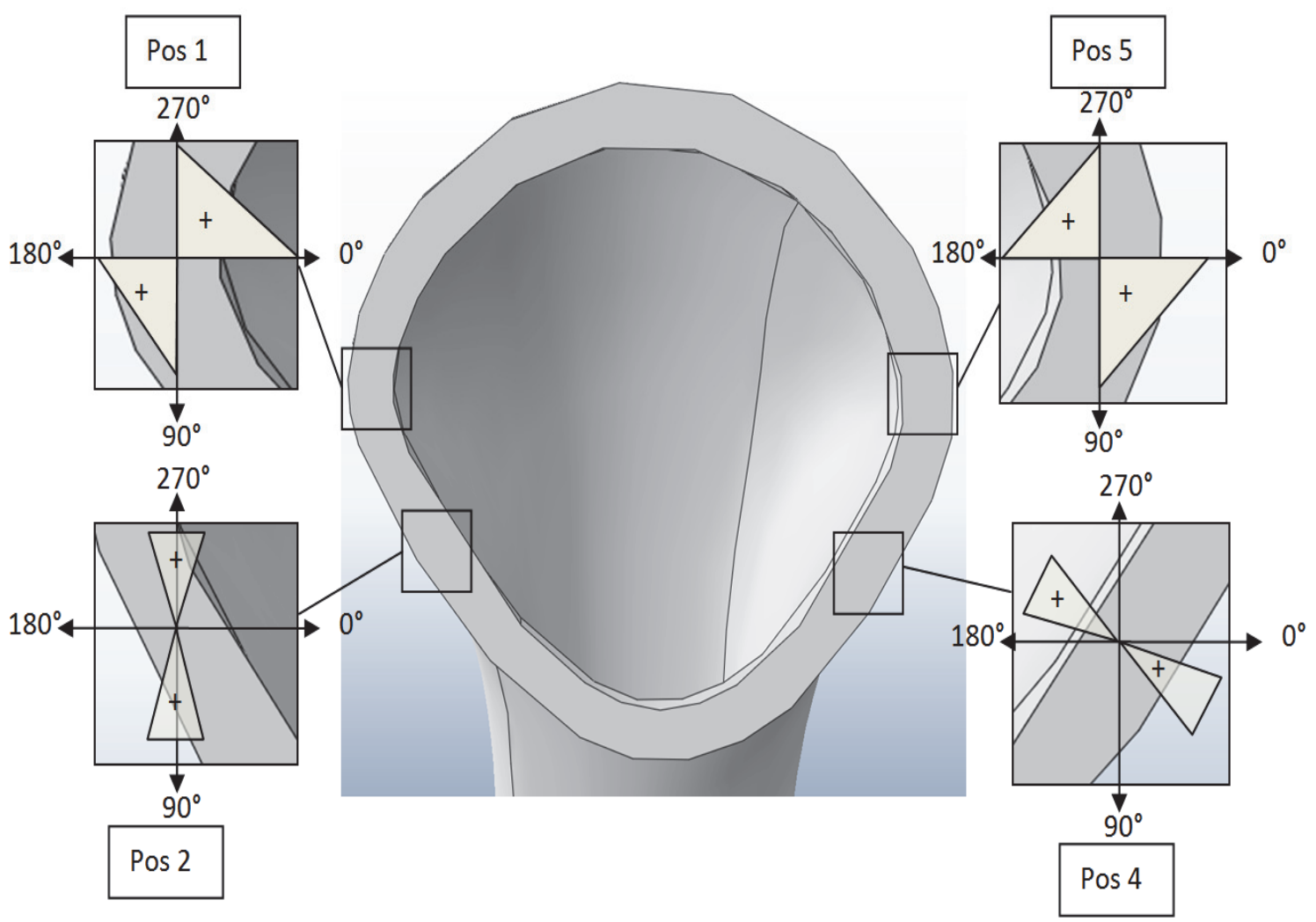

Figure 12: The orientations of the most critical crack for $(\mathrm{KI}>0)$.

Comparison of KII and KIII for different positions of the crack in the proximal part of the cement

Fig. 13 and show the distribution of the Mode II stress intensity factor on the front of a crack emanating from a cavity as a function of crack orientation, along the front for different positions of the proximal area.

According to these results from KI; the most dangerous positions are positions 1 and 5 since KI has significant positive values and therefore a crack opening, which is favorable for the other modes II.

When analyzing crack opening mode curves (Figs. 19) we find that the maximum KII value is out of crack opening range. We anticipate that the most dangerous crack orientations occur at the outer bounds of the range (Fig. 21).

Our analyses of crack behavior in the proximal region of the mantle have identified specific crack orientations and circumferential locations that may lead to the crack propagation. K. A Mann found that only existing of radial cracks in the proximal region of cement mantle could propagate [18]. D. Kytyr and Murphy found in their experimental study that the cracks propagation directions are distributed normally about the direction perpendicular to the applied load [26, 27]. These independent studies both provide findings that support our results.

Fig. 14 show the distribution of the Mode III stress intensity factor on the front of a crack emanating from a cavity as a function of crack orientation, along the front for different positions of the proximal area.

In position 1, the plane shear mode of this crack is greater than that in shear anti-planes, which promotes a propagation of crack in mixed mode (mode of opening + shear plane).

On the other hand, for position 5, larger K III values are observed than the plane shear mode (KII); which predicts crack propagation in mixed mode between the opening mode and the anti-plane shear mode. Orthopedic cement must withstand the mechanical stresses on the femoral head that can lead to the creation and propagation of crack and subsequent loosening of THP.

The most critical orientations which make the crack likely to propagate in mode II and III, lies on the outer limits of the crack opening range.

The crack at these positions may propagate under combined of all 3 modes of propagation, If the crack exists in the proximal zone in the remaining positions, it is in closed state, so it does not make any threat for the cement failure. 

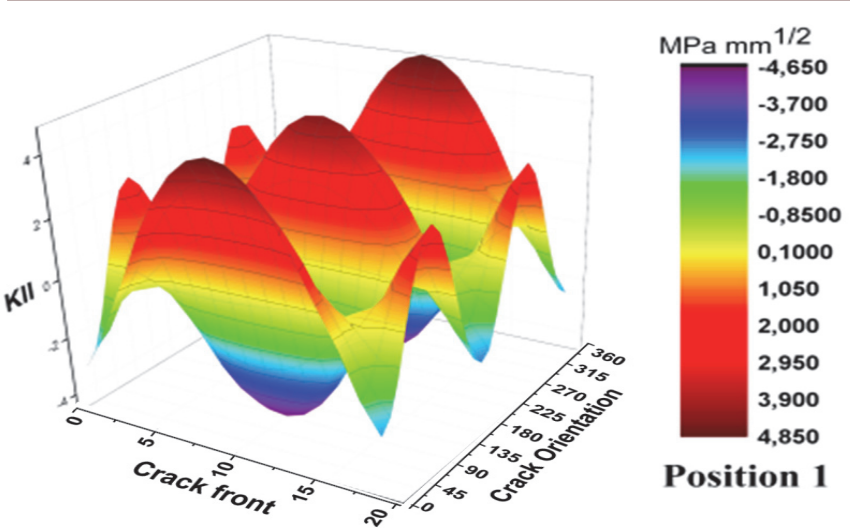

Position 1

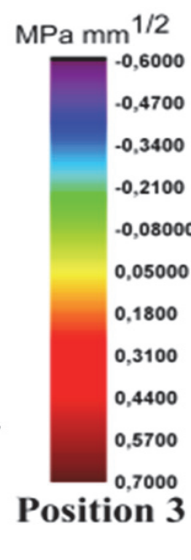

MPa $\mathrm{mm}^{1 / 2}$
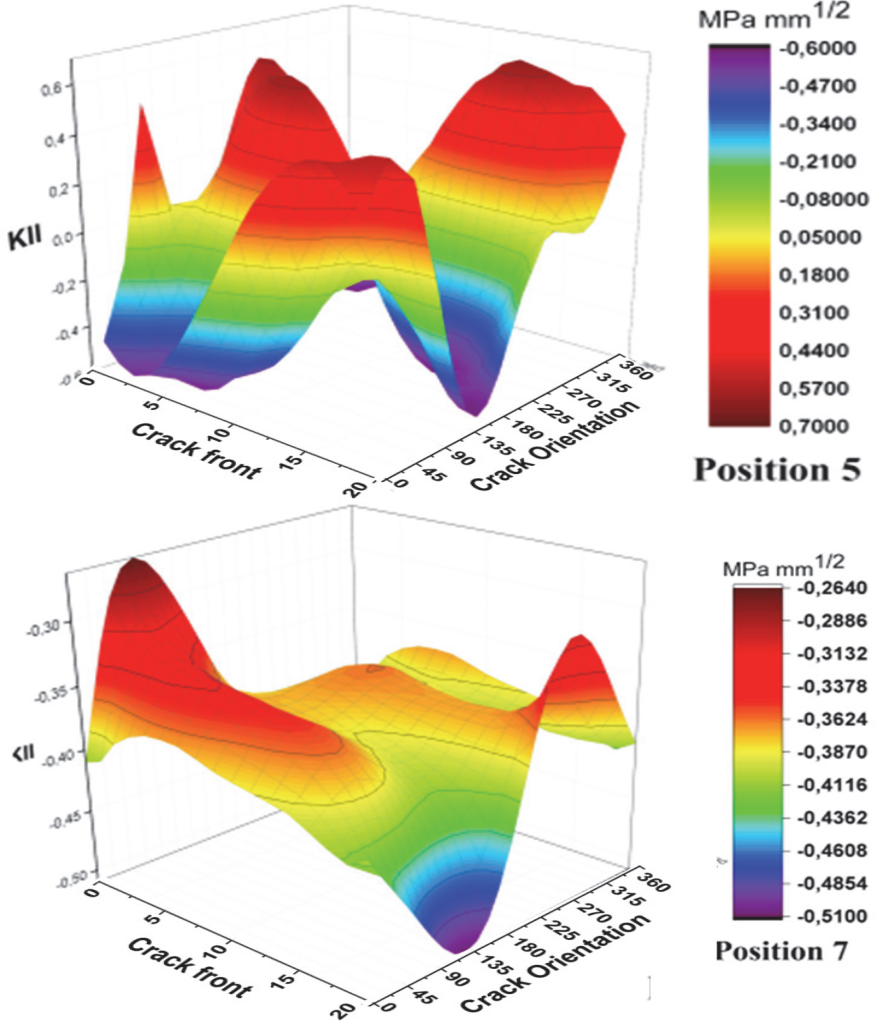

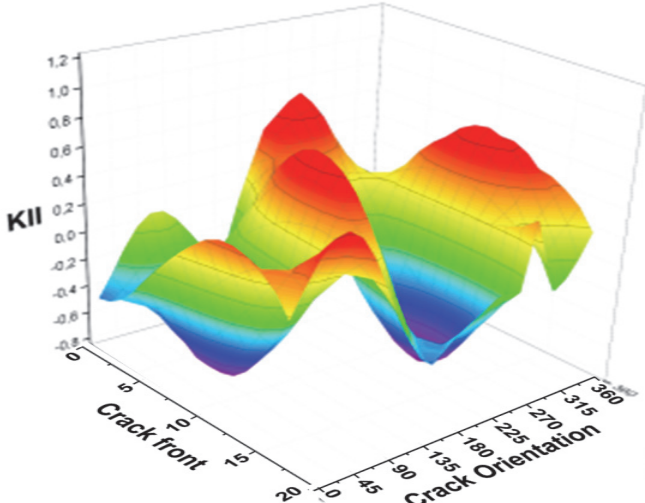

MPa mm ${ }^{1 / 2}$

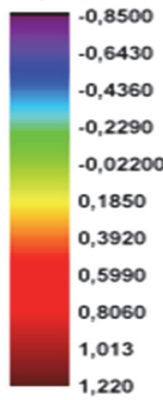

Position 2

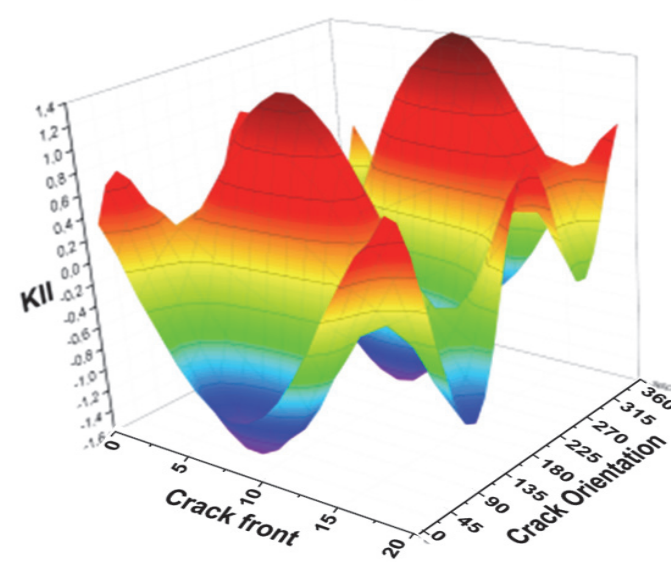

$\mathrm{MPa} \mathrm{mm}{ }^{1 / 2}$

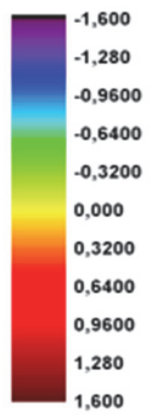

Position 4

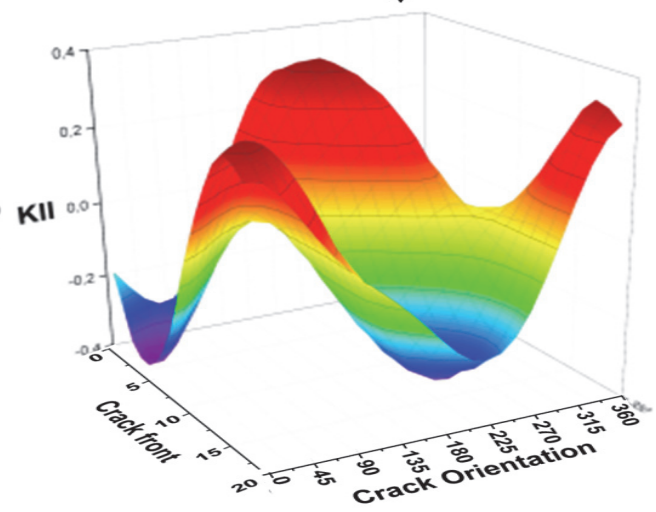

MPa $\mathrm{mm}^{1 / 2}$

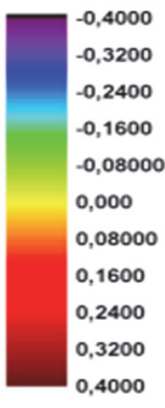

Position 6

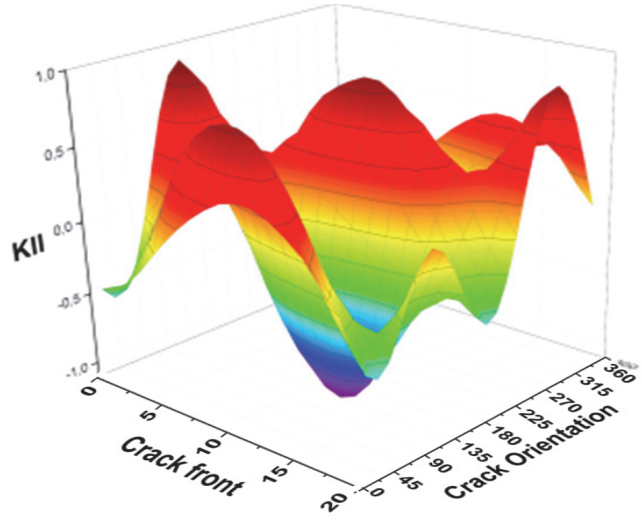

MPa $\mathrm{mm}^{1 / 2}$

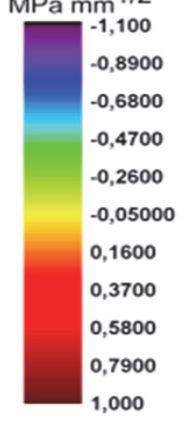

Position 8

Figure 13: Distribution of the KII on the crack front according to the orientation of the crack. 

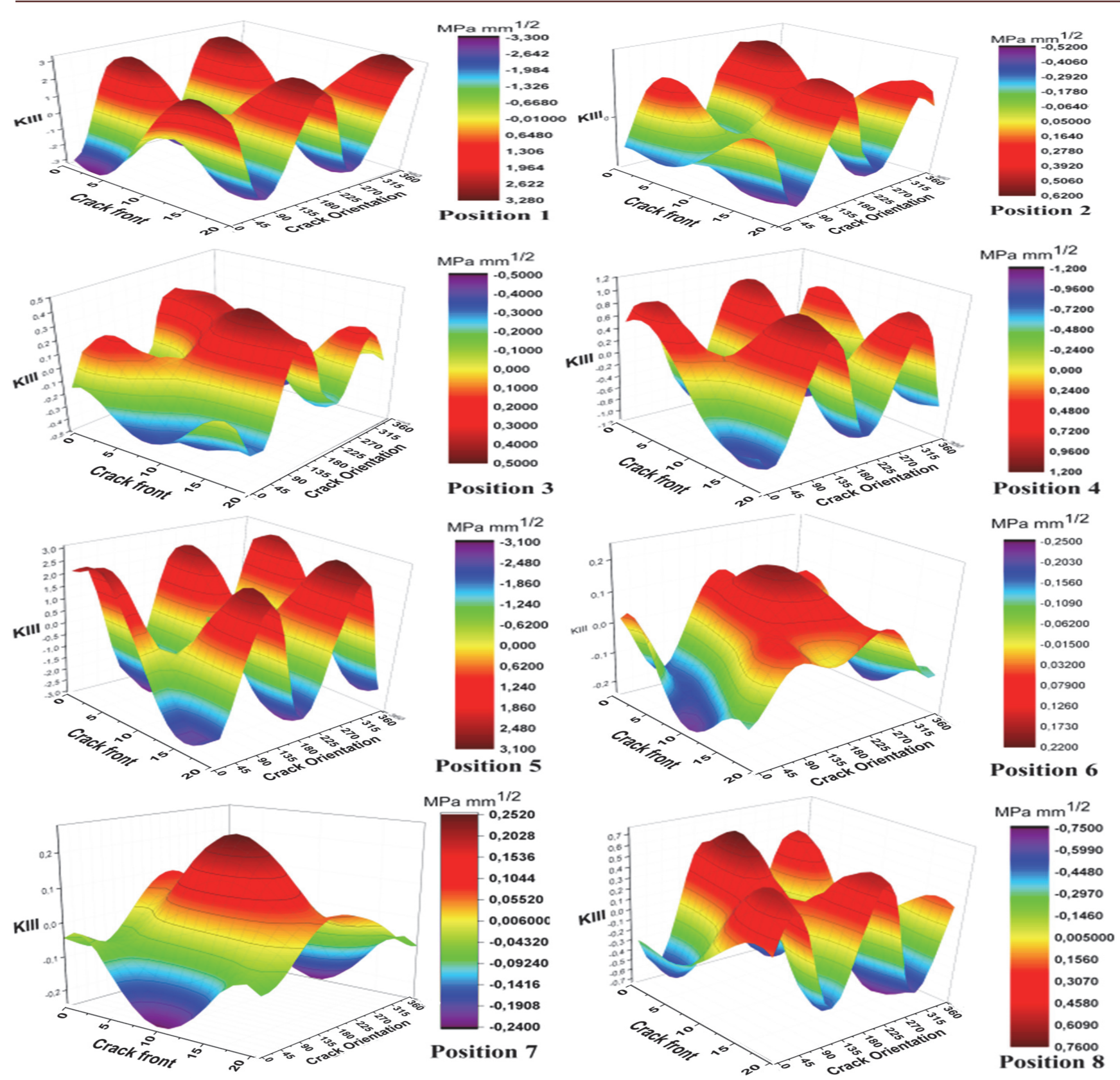

Figure 14: Distribution of KIII on the crack front according to the orientation of the crack.

\section{CONCLUSION}

$\mathrm{O}$ ur results clearly show that the existence of a cavity in the orthopedic cement considerably increases the level of stress in this material and consequently the risk of loosening of the total hip prosthesis. In this case the probability of rupture is closely related to the nature of the defect, its position and its shape. In the zone of high concentration of stress, the cracks emanate from a cavity propagates in the same direction whatever the position and the shape of the cavity, because the crack is too small to disturb the stress field which surrounds. So the known direction of propagation, a provide a method to stop the spread (addition of metal particle or reinforcement by a grid).

The propagation of an initialized fissure of a cavity in the cement of the femoral part is strong possible for both positions 1 and 5 of the proximal zone. These two positions are located in the direct contact area between orthopedic cement and cortical bone. In other words, the cement can rupture by creating a crack in the proximal area. A crack initiated in 
position 1 develops in a mixed mode between the aperture and plant shear mode, whereas those initiated in position 5, can propagate in mixed mode between the open mode and shear anti plan. A crack with a length can initiate from a cavity located in the first and fifth position of the proximal zone.

\section{REFERENCES}

[1] Maloney, W. J. Jasty, M. Burke, D. W., O'connor, D. O., Zalenski, E. B., Bragdon, C. and Harris, W. H. (1989). Biomechanical and histologic investigation of cemented total hip arthroplasties. A study of autopsy-retrieved femurs after in vivo cycling. Clinical orthopaedics and related research, (249), pp. 129-140.

[2] Bhambri, S. K. and Gilbertson, L. N. (1995). Micromechanisms of fatigue crack initiation and propagation in bone cements. Journal of Biomedical Materials Research, 29(2), pp. 233-237. DOI: 10.1002/jbm.820290214.

[3] Jasty, M., Maloney, W. J., Bragdon, C. R., O'connor, D. O., Haire, T. and Harris, W. H. (1991). The initiation of failure in cemented femoral components of hip arthroplasties. The Journal of bone and joint surgery. British volume, 73(4), pp. 551-558.

[4] Zant, N. P., Wong, C. K. and Tong, J. (2007). Fatigue failure in the cement mantle of a simplified acetabular replacement model. International journal of fatigue, 29(7), pp. 1245-1252. DOI: 10.1016/j.ijfatigue.2006.10.013

[5] Boulenouar, A., Benouis, A. and Benseddiq, N. (2016). Numerical modelling of crack propagation in cement PMMA: Comparison of different criteria. Materials Research, 19(4), pp. 846-855. DOI: 10.1590/1980-5373-MR-2015-0784.

[6] Falkenberg, A., Drummen, P., Morlock, M. M. and Huber, G. (2019). Determination of local micromotion at the stem-neck taper junction of a bi-modular total hip prosthesis design. Medical engineering \& physics, 65, pp. 31-38. DOI:10.1016/j.medengphy.2019.01.003.

[7] Benouis, A., Zagane, M. S., Boulenouar, A., Serier, B. and Belgherras, M. E. (2018). 3D FE analysis of the behavior of elliptical cracks on orthopedic cement of the total hip prosthesis. Journal of Theoretical and Applied Mechanics, 56. DOI: $10.15632 /$ jtam-pl.56.3.803.

[8] Kutzner, K. P., Freitag, T., Bieger, R., Reichel, H., Pfeil, J., Ignatius, A. and Dürselen, L. (2018). Biomechanics of a cemented short stem: Standard vs. line-to-line cementation techniques. A biomechanical in-vitro study involving six osteoporotic pairs of human cadaver femurs. Clinical Biomechanics, 52, pp. 86-94.

DOI:10.1016/j.clinbiomech.2018.01.004.

[9] Benbarek, S., Bouiadjra, B. A. B., El Mokhtar, B. M., Achour, T. and Serier, B. (2013). Numerical analysis of the crack growth path in the cement mantle of the reconstructed acetabulum. Materials Science and Engineering: C, 33(1), pp. 543-549. DOI: 10.1016/j.msec.2012.09.029.

[10] Persson, C., Baleani, M., Guandalini, L. and Viceconti, M. (2006). The effect of gentamicin on the fracture properties of bone cement. Journal of Biomechanics, (39), pp. S591-S592. DOI: 10.1111/j.1460-2695.2007.01109.x.

[11] Dalstra, M. and Huiskes, R. (1995). Load transfer across the pelvic bone. Journal of biomechanics, 28(6), 715-724.

[12] Achour, T., Tabeti, M. S. H., Bouziane, M. M., Benbarek, S., Bouiadjra, B. B. and Mankour, A. (2010). Finite element analysis of interfacial crack behaviour in cemented total hip arthroplasty. Computational Materials Science, 47(3), pp. 672-677. DOI: 10.1016/j.commatsci.2009.10.007

[13] Sahli, A., Benbarek, S., Wayne, S., Bachir Bouiadjra, B. A. and Serier, B. (2014). 3D crack behavior in the orthopedic cement mantle of a total hip replacement. Applied Bionics and Biomechanics, 11(3), pp. 135-147. DOI: 10.12989/sem.2018.66.1.037.

[14] Harrigan, T. P., Kareh, J. A., O'Connor, D. O., Burke, D. W. and Harris, W. H. (1992). A finite element study of the initiation of failure of fixation in cemented femoral total hip components. Journal of Orthopaedic Research, 10(1), pp. 134-144.

[15] Sinnett-Jones, P. E., Browne, M., Ludwig, W., Buffiere, J. Y. and Sinclair, I. (2005). Microtomography assessment of failure in acrylic bone cement. Biomaterials, 26(33), pp. 6460-6466.

[16] Solidworks Software. Dassault System.

[17] Murphy, B. P. and Prendergast, P. J. (2000). On the magnitude and variability of the fatigue strength of acrylic bone cement. International Journal of Fatigue, 22(10), pp. 855-864.

[18] Mann, K. A., Gupta, S., Race, A., Miller, M. A., Cleary, R. J. and Ayers, D. C. (2004). Cement microcracks in thinmantle regions after in vitro fatigue loading. The Journal of arthroplasty, 19(5), pp. 605-612.

DOI: $10.1016 /$ j.arth.2003.12.080. 
[19] Wirtz, D. C., Schiffers, N., Pandorf, T., Radermacher, K., Weichert, D. and Forst, R. (2000). Critical evaluation of known bone material properties to realize anisotropic FE-simulation of the proximal femur. Journal of biomechanics, 33(10), pp. 1325-1330. DOI: 10.1016/S0021-9290(00)00069-5.

[20] Kim, B., Moon, B., Mann, K. A., Kim, H. and Boo, K. S. (2008). Simulated crack propagation in cemented total hip replacements. Materials Science and Engineering: A, 483, pp. 306-308. DOI: 10.1016/j.msea.2007.01.171.

[21] Pacific Research Labs. Biomed Town. https://www.biomedtown.org.

[22] Pustoc'h, A. and Cheze, L. (2009). Normal and osteoarthritic hip joint mechanical behaviour: a comparison study. Medical \& biological engineering \& computing, 47(4), 375. DOI: 10.1007/s11517-009-0457-9.

[23] Pauwels, F. (2013). Atlas zur Biomechanik der gesunden und kranken Hüfte: Prinzipien, Technik und Resultate einer kausalen Therapie. Springer-Verlag.

[24] Topoleski, L.D.T., Duchegne, P., Cucheyne, P. and Cuckler, J.M.(1990). A fractographic analysis of in vivo polymethylmethacrylate bone cement failure mechanisms, J Biomed Mater Res, 24, pp. 135-154.

[25] Flitti, A., Ouinas, D., Bouiadjra, B. B. and Benderdouche, N. (2010). Effect of the crack position in the cement mantle on the fracture behavior of the total hip prosthesis. Computational Materials Science, 49(3), pp. 598-602. DOI: 10.1016/j.commatsci.2010.05.056.

[26] Kytyr, D., Doktor, T., Jirousek, O., Zlamal, P. and Pokorny, D. (2011). Experimental and numerical study of cemented bone-implant interface behavior. Frattura ed Integrita Strutturale, 5(15), pp. 5-13. DOI: 10.3221/IGFESIS.15.01.

[27] Murphy, B. P. and Prendergast, P. J. (2002). The relationship between stress, porosity, and nonlinear damage accumulation in acrylic bone cement. Journal of Biomedical Materials Research: An Official Journal of The Society for Biomaterials, The Japanese Society for Biomaterials, and The Australian Society for Biomaterials and the Korean Society for Biomaterials, 59(4), pp. 646-654. DOI: 10.1002/jbm.10028.

\section{NOMENCLATURE}

Total Hip Arthroplasty (THP)

Polymethylmethacrylate (PMMA). 